Article

\title{
Study on the Functional Improvement of Economic Damage Assessment for the Integrated Assessment Model
}

\author{
Changxin Liu ${ }^{1}$, Hailing Zhang ${ }^{2, *}$ and Zheng Wang ${ }^{1, *}$ \\ 1 Institutes of Science and Development, Chinese Academy of Sciences, Beijing 100190, China; \\ liuchangxin@casisd.cn \\ 2 State Key Joint Laboratory of Environment Simulation and Pollution Control (SKLESPC), and School of \\ Environment, Tsinghua University, Beijing 100084, China \\ * Correspondence: zhanghailing@mail.tsinghua.edu.cn (H.Z.); wangzheng@casisd.cn (Z.W.)
}

Received: 2 January 2019; Accepted: 25 February 2019; Published: 28 February 2019

check for

\begin{abstract}
The economic damage function of the integrated assessment model (IAM) is used to quantify the economic loss caused by climate change, and it is quite important for coupling the economic system and natural system in a model. However, there are many shortcomings of the damage function in the current IAM. The most important shortcoming is that the only climatic factor in the damage function is the global annual mean temperature rise, which would result in the estimation deviating from reality. We improved the damage function by introducing extreme climate change events. Additionally, the improved damage function is applicable to the regional characteristics by using regional climate change data. The extreme climate event information is extracted with the categories of the disasters. The damage function is set up by using the Ordinary Least Square (OLS) method based on the climate data and economic loss data. The results show that the improved IAM damage function can better reflect the actual climate change economic loss in China, making it more reasonable. This paper provides an important method and technical solution for the realization of an effective connection between the disaster damage function of the integrated assessment model and the climate elements of the Earth system model.
\end{abstract}

Keywords: integrated assessment model; damage function of climate change; precipitation; extreme climate event

\section{Introduction}

Climate change could have great impact on natural systems, ecosystems, and human socioeconomic systems, but the effects are comprehensive, multi-regional, and multi-disciplinary. Proper assessment of the damage caused by climate change to the entire socioeconomic system is an important research issue in climate change research, which is directly related to global social welfare and climate change response strategies. As pointed out in a review paper published by Revesz et al. in Nature, the climate change economic model reported by the The Intergovernmental Panel on Climate Change (IPCC) Fifth Assessment underestimates the dangers of future climate change [1]. Therefore, it is imperative to improve the model and fill the research gaps in many climate issues, such as the economic response of developing countries and the assessment of the damage caused by extreme climates. In addition, the effects of historical temperature changes indicate that society and the economy may be more "fragile" than predicted by the model; compared with changes in the average temperature, weather variability is more likely to cause harm, especially to crops and food security. The integrity and accuracy of the damage function (especially in terms of catastrophic losses, conflicts, 
weather variability, feedback on economic growth, etc.) are still uncertain, and future losses due to climate change may be higher $[1,2]$.

In the economic impact assessment of climate change, the integrated assessment model (IAM) integrates the climate system and the economic system into the same framework and thus is a mainstream tool for climate policy research [2]. There are many kinds of IAMs. According to model methodology, IAM can be divided into three categories: A computable general equilibrium model, inter-temporal optimization model, and simulation model. (1) Computable general equilibrium models, such as the Economic Projection and Policy Analysis (EPPA) model of Massachusetts Institute of Technology (MIT) and the Structural growth model (SGM) model from the Pacific northwest laboratory. Computable General Equilibrium model (CGE) can provide very useful information when studying future greenhouse gas (GHG) and evaluation strategies of GHG reductions. (2) The inter-temporal optimal model, such as the Regional Integrated model of Cliamte and the Economy (RICE) from Yale and MERGE. The economic module of dynamic or inter-temporal optimization models are currently not based on the sector level as CGE model. However, compared with the CGE model, it has better flexibility in depicting individual decision-making and responses to future events. (3) The simulation model, such as the ICAM model of Carnegie Mellon University and IMAGE model from the Netherlands national institute of public health. Scenario simulation models usually do not need to spend time to find the optimal solution. The modeling structure also often takes the bottom-up model. Among these IAMs, the inter-temporal optimal models are the only ones that integrate the impacts of climate change. Therefore, the damage function we focused on is based on this category of IAMs. With the continued development of IAM, its coupling with large climate models and even Earth system models has become an inevitable trend $[3,4]$. The function in the IAM that reflects the economic impact of climate change is named the damage function [5-7], which can be used as an important interface for the coupling of economic systems and natural systems in the integrated assessment model to quantify climate-related economic damage. The coupling of damage functions refers to the influence mechanism of the economic system on the climate model and the feedback mechanism of the climate model on the economy [8,9]. The DICE model [10], RICE model [11], Tol's FUND model [8,12-16], Peck and Teisberg's CETA model [17], and Hope's PAGE model [18] all use this mechanism to assess the economic impact of climate change.

However, there are some drawbacks of the damage function in IAMs, thus leading to a bottleneck that limits the development of the IAM.

First, many IAMs use the temperature rise as the only climate change factor, and directly link economic losses with temperature rise, while information, such as precipitation, is not included [8]. This is due to the fact that, in the early IAM, the simplified statistical climate system model is used for coupling with socioeconomic models. For example, the climate module of the RICE model considers only temperature and radiation forcing, so the modules do not reflect information, such as precipitation, making it difficult to reflect the economic losses related to other such climate change factors. With the gradual enrichment and improvement of IAMs, climate modules have become increasingly complex. Many large climate models and even Earth system models have begun to meticulously calculate changes in temperature and precipitation in each region. However, there is currently no IAM damage function that closely interfaces with large climate models by using this climate information. Some recent research paid attention to introducing precipitation into the assessment of economic loss from climate change by using the simulation result of GCM models [19].

Second, it is often the extreme weather events brought about by climate change that have a huge impact on the economy. IAMs often avoid the economic loss information of many disaster categories and cannot directly describe it $[4,20,21]$. As the global average temperature increases, the intensity and frequency would usually increase. However, the relationship of the average temperature and the frequency of extreme climate change events is complex across regions and time. Thus, the use of the annual average temperature rise to reflect climate change losses inevitably leads to greater uncertainty. From the perspective of the coupling of IAMs and large-scale climate models, large-scale climate 
models can export extreme temperature and precipitation information in the region. It can be said that the current IAM filters climate change information through the large-scale climate model, resulting in insufficient coupling. Therefore, in the IAM, not only do the average climate change indicators need to be considered, but extreme climate change indicators should also be considered.

However, it should be stated that we should clearly distinguish between the concepts of the damage caused by meteorological events and the damage caused by climate change. Floods, droughts, and extreme temperature events occur not only as a result of climate change. These extreme meteorological events have been occurring for millennia. The difference is that they may now be occurring at a higher frequency as a result of climate change. However, it is hard to calculate which part is caused by climate change from the damage caused by meteorological events for each year. However, the most important thing for IAMs, which are used to guide decision makers, is to calculate the differences of economic loss with the different mitigation targets, which can surely be thought to be caused by climate change. From this point of view, setting up a damage function by meteorological events is also meaningful. In this paper, we set up the damage function by meteorological events.

Finally, as the global warming occurs, extreme climate events may vary from region to region, thus it is the local climate change rather than the global average climate change that determines the local economic loss. Thus, we used regional climate data to rebuild the damage function of the IAM.

In terms of the economic impact assessment of climate change, many researchers suggest that the assessment of precipitation, extreme climate events, and the economic impacts of regional climate change are important for the development of the IAM. However, these three aspects are not reflected in the current comprehensive IAM, including the six integrated assessment models adopted in the IPCC Fifth Assessment Report, which has become a hindrance to further development of the coupling of IAM with large-scale climate models and even Earth system models. In view of the key scientific problems existing in the IAM coupling mechanism, based on the previous research, this paper achieves breakthroughs and improvements in the IAM damage function, and compensates for the shortcomings of the feedback mechanism of climate change's impact on the economy.

\section{Materials and Methods}

\subsection{The Data}

\subsubsection{Climate Change Indicators}

Changes in the frequency and intensity of extreme weather events induced by climate change are likely to have a significant impact on human socioeconomics and the environment [22,23]. The IPCC Fourth Assessment Report (AR4) shows that people are increasingly concerned about changes in the frequency and intensity of extreme events caused by their own influence [24]. Extreme temperature and extreme precipitation are important components of extreme climate events. Many scholars at home and abroad have conducted a series of studies on temperature and precipitation data at different spatial and temporal scales in the past [25-28], trying to find trends in the frequency and intensity of extreme temperatures and precipitation events in history, but the results are not the same due to different research areas, selection times, and methods [29].

In the selection of extreme climate events, the most commonly used is the absolute threshold method, which determines the threshold for extreme climate events based on observational experience. For example, when the maximum temperature is $\geq 35^{\circ} \mathrm{C}$, it is regarded as high-temperature weather, and a minimum temperature of $\leq 0{ }^{\circ} \mathrm{C}$ is low-temperature weather. Daily precipitation of $\geq 50 \mathrm{~mm}$ is heavy rain, etc. When an element exceeds its threshold, an extreme climate event is considered to have occurred [30,31]. However, if such an approach is adopted in larger fields, there may be problems where extreme weather events are too frequent in some regions and rarely occur in others, which can easily lead to erroneous information [22]. Therefore, it is generally accepted that the use of probability density distribution functions (such as Gamma distribution [32,33] and edge distribution [22]) can help us determine the annual extreme temperature (precipitation) value and 
extreme temperature (precipitation) threshold. For example, an event of $\geq 95 \%$ or $\leq 5 \%$ of the percentile is considered to be close to the actual situation [34]; this concept of relative thresholds tends to be more general and comparable [35], taking into account regional differences in temperature and precipitation. The threshold of extreme temperature and precipitation events in various regions is determined by local temperature and precipitation conditions, which can better reflect the regional extreme characteristics and different kinds of temperature and precipitation changes. With reference to the Expert Group on Climate Change Detection and Indicators (ETCCDI), the method of defining extreme climate event indicators with relative thresholds is also a widely used and recognized method in the field of extreme climate event research [27,36-38].

With reference to the method of defining extreme climate indicators with the ETCCDI relative threshold, the method of extracting extreme temperature events used in this paper is to arrange the temperature sequence of each month of a year in ascending order, with the value at the 95th (5th) percentile of the temperature sequence as the extreme. If the temperature of a certain month exceeds the upper threshold, it indicates that an extreme high-temperature event occurred in that month. If the temperature of a certain month is below the threshold, it indicates that an extreme low-temperature event occurred in that month. The number of months during the year when the monthly temperature exceeds (is below) the upper (lower) threshold of the extreme temperature events is called the frequency of extreme high-temperature (low-temperature) events, and the ratio of the sum of extreme temperature values to the corresponding frequency is called the intensity of the extreme high-temperature (low-temperature) event. The upper (lower) threshold of the extreme precipitation event is extracted from the precipitation data. By the same token, there are methods for calculating the frequency and intensity of extreme flood events and extreme drought events. The implementation of the extreme climate indicator extraction program relies mainly on the development in the MATLAB programming platform. China's temperature and precipitation data come from the China Statistical Yearbook.

\subsubsection{Economic Loss Indicators}

Data on direct economic losses induced by climate change in China are from the Statistical Yearbook of Meteorological Disasters (2005-2016). Figures 1 and 2 show the evolution of China's direct economic losses induced by climate change over the years of 2004-2015. From 2004 to 2015, China's direct economic losses induced by climate change totaled 360.222 billion yuan, with an average of 300.19 billion yuan, accounting for $0.74 \%$ of the Gross Domestic Product (GDP) in the same period, with an average ratio of $0.83 \%$. The most serious losses reached $1.23 \%$ in 2010, with 509.75 billion yuan.

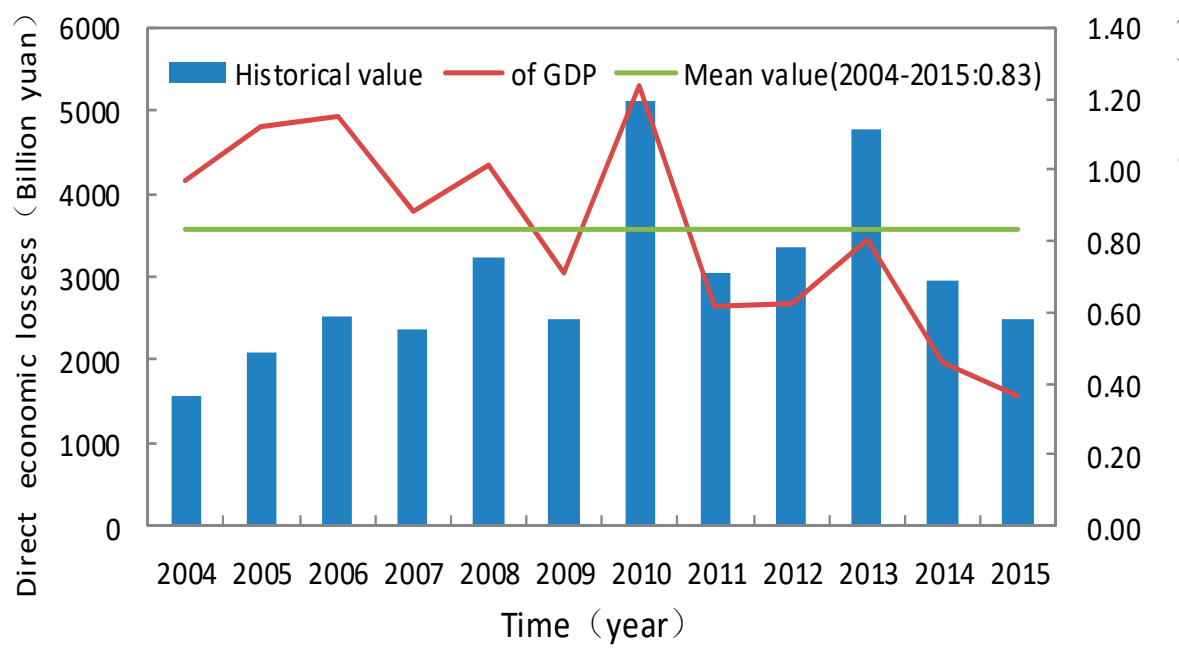

Figure 1. The direct economic losses caused by meteorological events in China (2004-2015). 


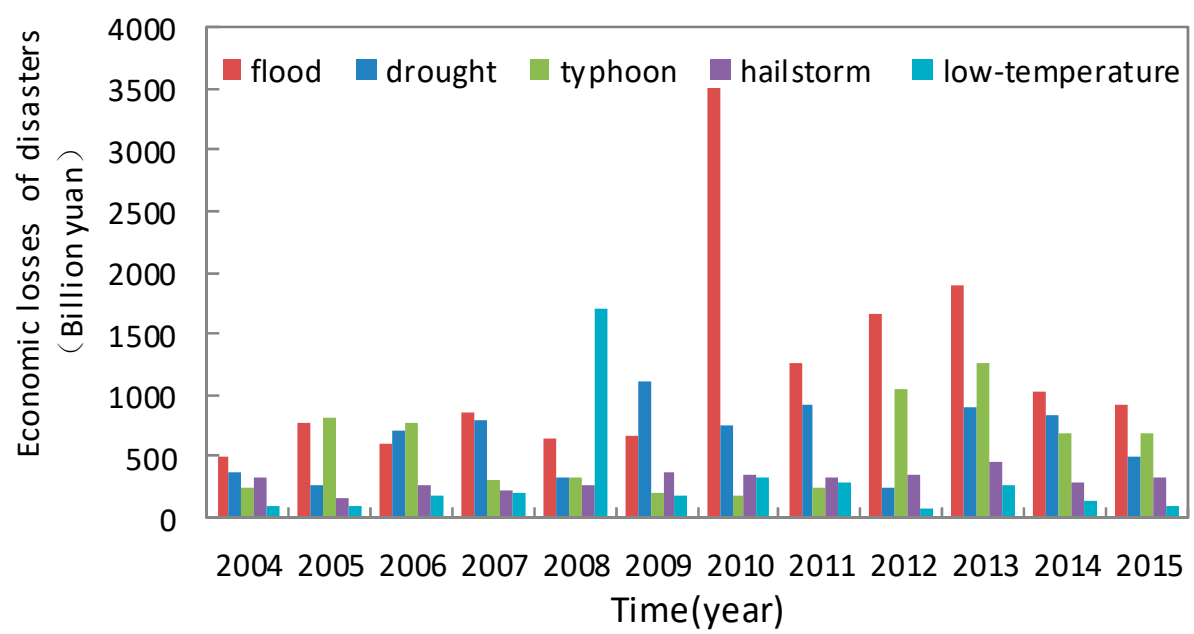

Figure 2. The direct economic losses caused by different extreme climate events in China (2004-2015).

From a subcategory perspective, this paper only considers extreme weather events associated with temperature and precipitation, namely floods, droughts, and low temperatures. From 2004 to 2015, the largest direct economic loss was caused by torrential rain and floods (landslides and mudslides), totaling 1429.57 billion yuan, with an interannual average of 119.13 billion yuan, accounting for $0.29 \%$ of the GDP in the same period. The economic loss in 2010 was the most serious, reaching 350.5 billion yuan, accounting for $68.8 \%$ of the total loss. Overall, the loss caused by floods in the country in 2010 was significantly higher than the average level since the 1990s; it was a year of heavy rain and flood losses. From 2004 to 2015, the direct economic losses caused by drought amounted to 768.87 billion yuan, with an annual average of 64.07 billion yuan, accounting for $0.16 \%$ of the GDP in the same period, and the economic loss in 2009 was the most serious. This was a year of drought losses, with a loss of 109.92 billion yuan, accounting for $44.1 \%$ of the total loss. From 2004 to 2015, the direct economic loss caused by low temperatures reached 358.68 billion yuan, with an average annual average of 29.89 billion yuan, accounting for $0.07 \%$ of the GDP in the same period, and the economic loss in 2008 was relatively serious, reaching 169.64 billion yuan, accounting for $52.3 \%$ of the total losses. Overall, in 2008, the low-temperature (freezing) loss and snowstorms covered a relatively large area of China and the loss was biased, resulting in more casualties than the perennial.

\subsection{The Method}

\subsubsection{The Improvement Mechanism of the IAM Damage Function}

Although the damage function of IAM is extremely important, it is very difficult to construct it at an early stage. The impact of climate change is widespread, including ecological damage, life and health damage, and economic damage, and there are huge uncertainties in its assessment. It is difficult to quantify losses in terms of ecological and life health, and many problems remain even in the case of economic losses that can be measured in monetary terms [39].

The main difficulty is that the damage function needs to comprehensively consider and summarize various loss situations, and it is important to consider the coupling of the model and the uncertainty. However, the data required for the construction of the damage function on climate change and its economic losses are relatively scarce [40]. The earliest loss assessment practice is the expert judgment method, that is, direct access to relevant experts to inquire about the extent of climate change impacts, such as [9], in which the economic loss is assessed by experts of meteorological disasters. Subsequently, meta-analysis was adopted by [41,42], and the basic idea is summarized or statistical analysis of early research results. The meta-analysis is done by first identifying the physical losses caused by climate change, including the number of house collapses, land inundations, personal injuries, and vehicle losses, from the extensive literature. Then, combined with the market analyzes aimed at identifying 
the value of resources at that time and the valuation technology of lost items, the loss is estimated; lastly, through statistics and other comprehensive methods, the relationship between climate change and economic impact is calculated. Among these studies, most work analyzed the cumulative damage function of the climate change effects, embedding them into climate change models [43].

At the same time, some scholars are starting to take another way. They think that instead of focusing on the absolute losses caused by climate change, it is better to pay attention to the relationship between climate change and the GDP. The GDP, climate change factors (temperature, precipitation, etc.), and production factors are directly analyzed by statistical regression. Mendelsohn adopted value variables and selected several countries to assess the economic impact of climate change on a sectoral basis from the year of 2010 to 2100 [44]. Since then, some scholars, such as [45] and [46], have also adopted statistical methods to study the impact of climate change. Meta-analysis and statistical methods have their own advantages and disadvantages. The advantage of statistical methods lies in the availability of data, which can be refined to a particular region and industry, while its disadvantage is the risk of the distortion of statistical data. The advantage of a meta-analysis is that the damage function is mechanical, but there are many disadvantages in a meta-analysis, mainly due to the small number of data samples.

So far, there are few existing studies that have introduced extreme climate change events into the damage function, thus this is the focus of the present paper. However, we would like to find the basic information between the economic loss of different disasters of climate change and the average and extreme climate change.

Within the context of China, to further determine the specific form of the multi-climate factor IAM damage function and clarify the improvement mechanism of the IAM damage function, this paper created a scatter diagram of the economic losses and various climate indicators.

(1) The relationship between regional economic losses and average climate indicators in China

Figure 3 shows a scatter plot of the overall economic loss in 31 provinces versus the average climate indicators. Overall, Figure 3a shows that the scatter plot of the total economic loss versus the annual average temperature is considered a weak quadratic relationship, while Figure $3 \mathrm{~b}$ shows a stronger quadratic relationship. Figure $3 \mathrm{c}$ shows that the scatter plot of the total economic loss versus the annual precipitation is a weaker quadratic relationship, while Figure $3 \mathrm{~d}$ shows a stronger quadratic relationship. From a statistical point of view, there is a suitable value (critical value) for temperature and precipitation. If the temperature or precipitation is higher or lower than the suitable value, it would result in varying degrees of direct economic losses.

Figure 4 is a scatter plot of the economic losses of the floods, droughts, and low temperatures in the 31 provinces of China. In terms of regions, Figure $4 a, b$, shows that, with the increase of annual precipitation, the economic loss of floods increases, and the positive correlation between the economic loss of floods and the annual precipitation is regarded as a quadratic relationship. Figure $4 \mathrm{c}, \mathrm{d}$ shows that, as the annual precipitation increases, the economic loss of drought becomes smaller, and the negative correlation of the economic loss of drought and the negative correlation of annual precipitation is regarded as a quadratic relationship. Figure $4 \mathrm{e}, \mathrm{f}$ shows that, as the annual average temperature increases, the low-temperature economic loss tends to be lower, and the negative correlation of the low-temperature economic loss and the average annual temperature is regarded as a quadratic relationship. Statistically speaking, the relationship between the various economic losses and average climate indicators is considered as a quadratic relationship, including the flood economic damage function, drought economic damage function, and low-temperature economic damage function. 

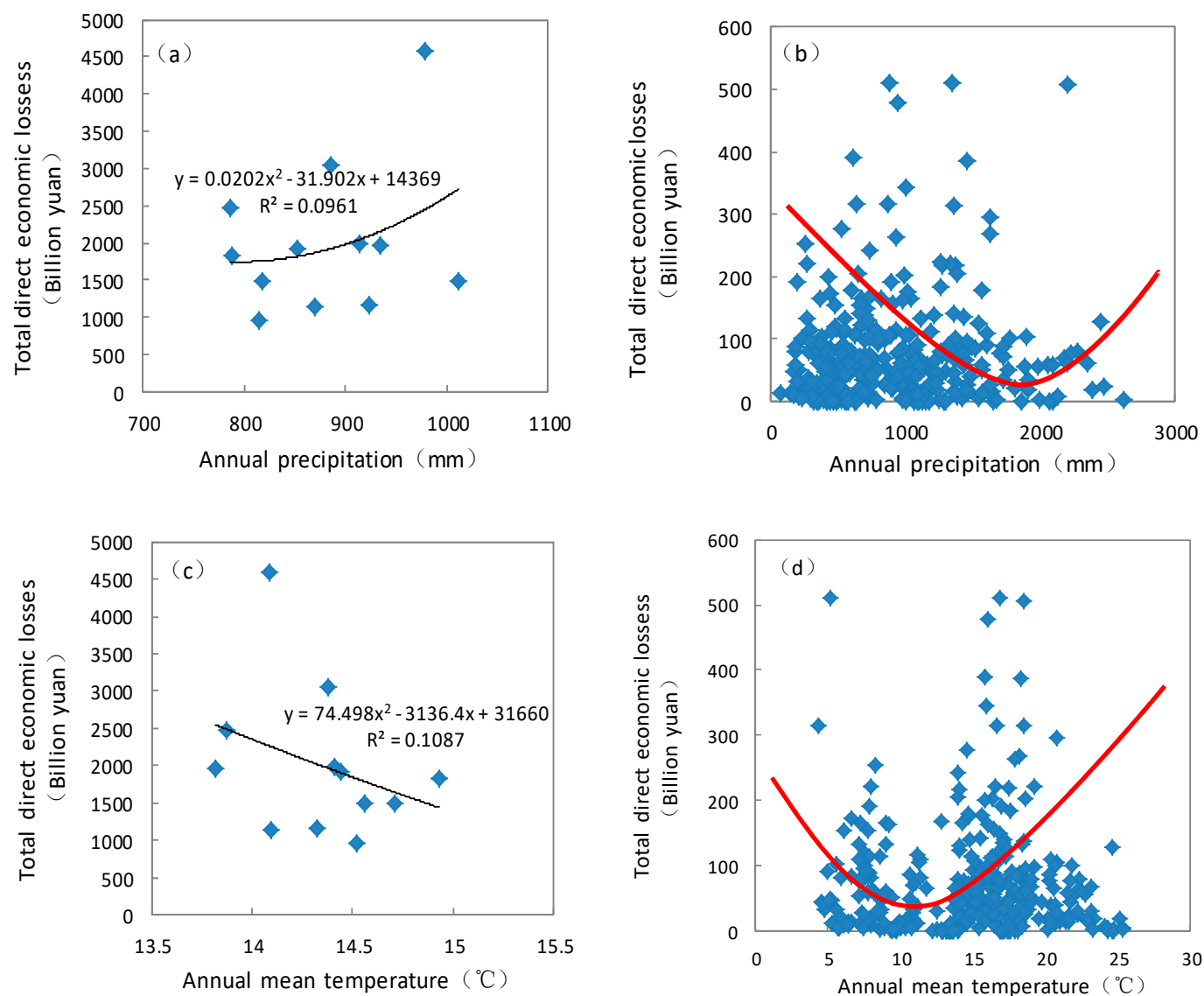

Figure 3. Scatter plot of the economic losses in China, the annual mean temperature, and the annual mean precipitation. (a) Scatter plot of the economic loss in China and the annual mean precipitation at the country level; (b) scatter plot of the economic loss in China and the annual mean precipitation at the provincial level; (c) scatter plot of the economic loss in China and the annual mean temperature at the country level; (d) scatter plot of the economic loss in China and the annual mean temperature at the provincial level.
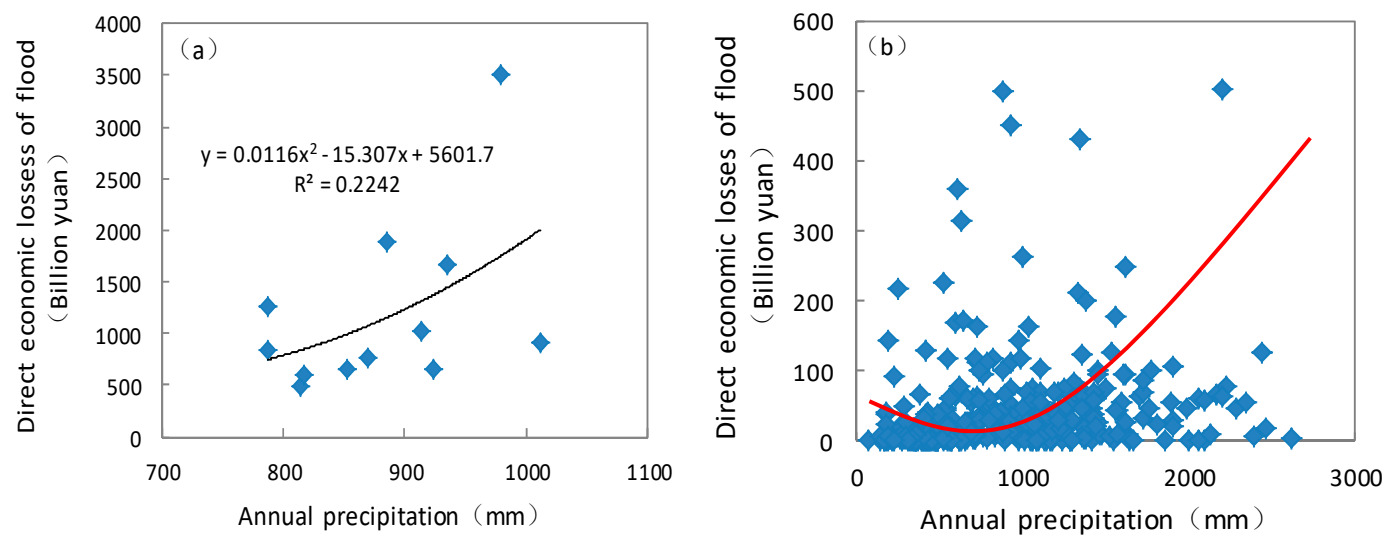

Figure 4. Cont. 

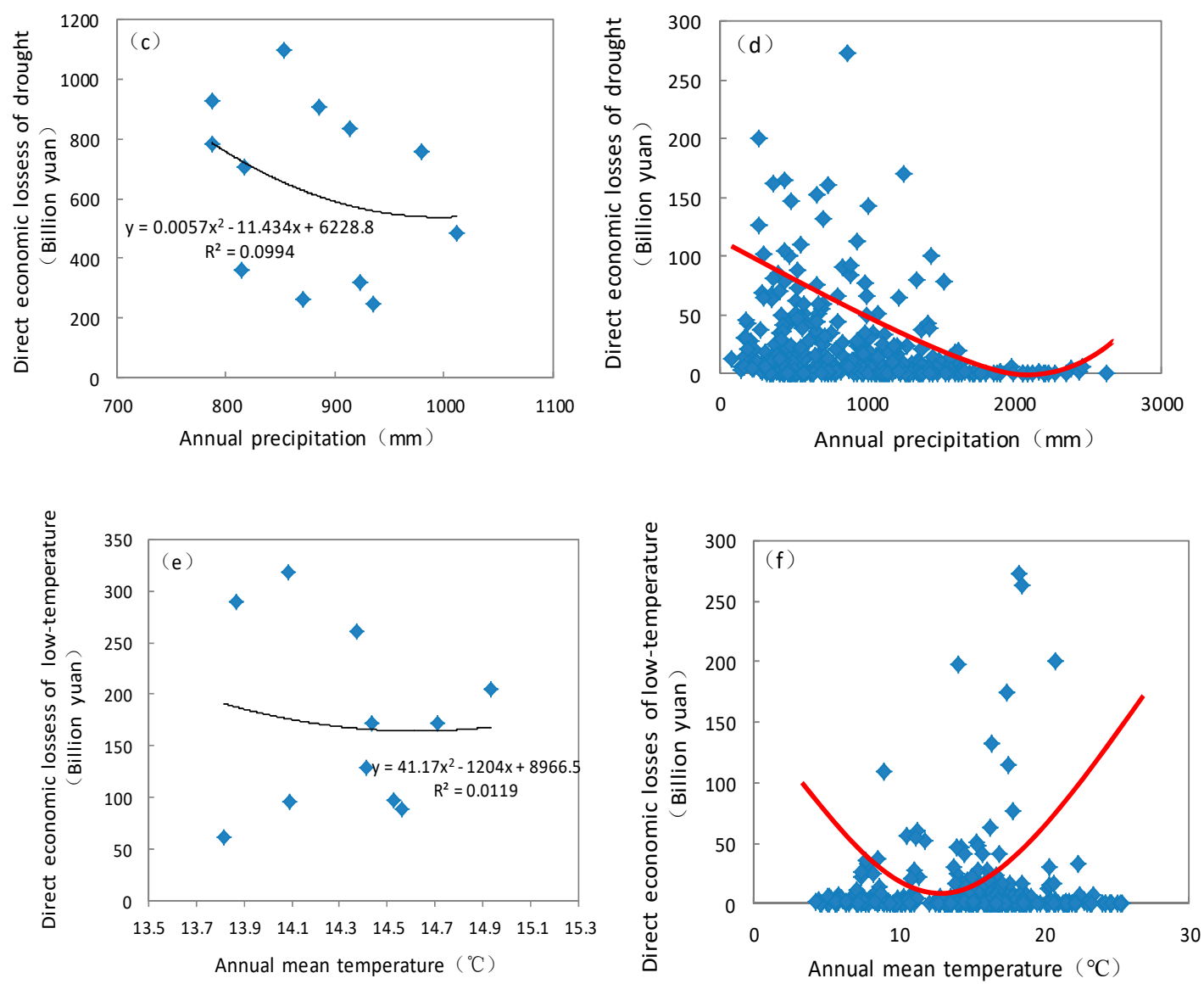

Figure 4. Scatter plot of the economic loss of China and the different extreme climate change events. (a) Economic losses caused by flood and precipitation; (b) economic losses caused by flooding and precipitation at the provincial level; (c) economic losses caused by drought and lack of precipitation; (d) economic losses caused by drought and lack of precipitation at the provincial level; (e) economic losses caused by extreme low temperature and precipitation; (f) economic losses caused by extreme low temperature and precipitation at the provincial level.

(2) The relationship between regional economic losses and extreme climate indicators in China

In China, with the increase in flood intensity, the economic loss due to floods is greater, and the positive correlation between economic losses and flood intensity is seen as a linear relationship. As the intensity of a drought increases, the economic losses from the drought increase. As the low temperature intensity increases, the low-temperature economic loss increases. Statistically speaking, the relationship between the various economic losses and extreme climate indicators is considered a linear relationship that includes the flood economic damage function, drought economic damage function, and low-temperature economic damage function.

\subsubsection{The Framework for Constructing the Damage Function}

In this paper, which uses China as the study area, precipitation is introduced to make up for the economic impact of using only the temperature rise to reflect all climate change factors. The impact of regional climate change factors is refined. According to the climate change characteristics of the monthly scale temperature and precipitation, information on the extreme temperature and extreme precipitation events is extracted. The economic damage function is developed, classified by disaster, including average and extreme climate, and we changed the method to estimate the damage using the annual average of climate change in traditional IAMs. The IAM damage function of multi-climate factors, suitable for assessing regional characteristics in China, is constructed to reduce the uncertainty 
of the economic impact of climate change, and thus improve the IAM coupling mechanism and the comprehensive assessment model (Figure 5). This research provides an important interface and technical solutions to form an effective link between the disaster damage function of the integrated assessment model and the climate elements of the earth system model.

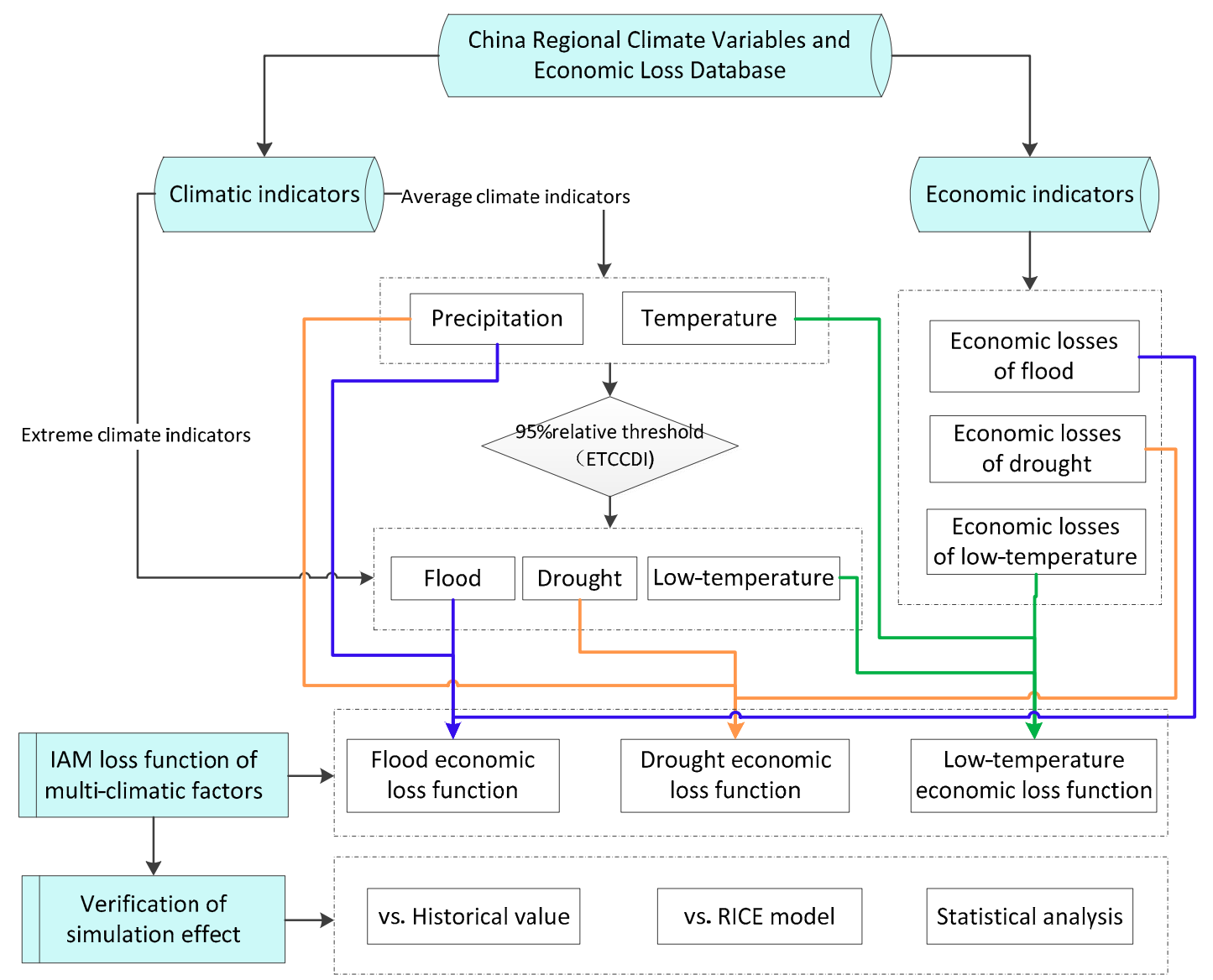

Figure 5. A framework for constructing the damage function.

With the help of econometric analysis software, such as SPSS Statistics 22.0 and Eviews 6.0, this paper analyzes the climate data and economic data, synthesizes the fitting effects of various analysis methods, and finally determines the type of the IAM damage function. The econometric and statistical analysis methods used include: Basic statistical analysis, multiple statistical regression analysis, panel data analysis, and gradual regression analysis.

\subsubsection{Construction of Multi-Climate Factor IAM Damage Function}

In the RICE model, the climate-to-economic feedback module is the damage function of the Nordhaus model (Nordhaus and Yang, 1996), in which the numerator indicates the economic cost of the mitigation of greenhouse gas, and the denominator indicates the extent to which the temperature rise affects economic production.

$$
\begin{gathered}
\Omega_{i, t}^{*}=\frac{1-b_{i, t} \mu_{i, t}}{1+\left(\frac{D_{0}}{9}\right) T_{t}^{2}} \\
Y_{-} \text {real }_{i, t}=\Omega_{i, t}^{*} Y_{i, t}=\left(1-A_{i, t}^{*}\right) Y_{i, t}
\end{gathered}
$$

wherein, $\Omega_{i, t}^{*}$ is the ratio of the real economic output, $Y_{-}$real $i_{i, t}$, to the theoretical economic output, $Y_{i, t}$, after being affected by temperature; $A_{i, t}^{*}$ is the ratio of the increase in temperature to the loss of economic output to the total theoretical output, $Y_{i, t}, T_{t}$ is the global average temperature rise during 
the period $\mathrm{t}$ (relative to the pre-industrial 1990 level), $b_{i, t}$ is the production-type emission reduction coefficient, $D_{0}$ is the GDP loss caused by the temperature rise of $3{ }^{\circ} \mathrm{C}$, and $\mu_{i, t}$ represents the emission reduction control proportion.

According to the improvement mechanism of the relationship between economic loss and various climate indicators in the damage function in Equations (3)-(7), the IAM damage function is improved by introducing the climate change factor gradually. This paper creatively introduces precipitation into the traditional IAM damage function, as in Equation (3). The frequency and intensity of extreme temperature and precipitation events is included. The economic impact of extreme climate events is reflected in the damage function. In addition, to further refine the economic impact of climate change, the climate damage function is constructed by each category, as in Equations (5)-(7).

With the introduction of the precipitation factors, the IAM damage functions, including temperature and precipitation, are constructed:

$$
\mathrm{A}^{*}=\mathrm{B}_{0} \cdot(\Delta \mathrm{T})^{2}+\mathrm{C}_{0} \cdot(\Delta \mathrm{P})^{2}+\mathrm{D}_{0} \cdot(\Delta \mathrm{P})+\mathrm{E}_{0}
$$

where $\mathrm{A}^{*}$ is the proportion of direct economic losses of climate change to the total economic output, $\Delta \mathrm{T}$ is the average annual temperature rise, $\Delta \mathrm{P}$ is the change of the annual precipitation, and $\mathrm{B}_{0}, \mathrm{C}_{0}, \mathrm{D}_{0}$, and $\mathrm{E}_{0}$ are parameters to be estimated. The data is from the historical statistic.

Continuing to introduce extreme climate indicators, damage functions, including temperature, precipitation, extreme temperature factors, and extreme precipitation factors, are established:

$$
\begin{gathered}
\mathrm{A}^{*}=\mathrm{a}\left(\mathrm{A}_{\mathrm{f}}+\mathrm{A}_{\mathrm{d}}+\mathrm{A}_{\mathrm{c}}\right) \\
\mathrm{A}_{\mathrm{f}}=\mathrm{B} 1_{0} \cdot(\Delta \mathrm{P})^{2}+\mathrm{C} 1_{0} \cdot(\Delta \mathrm{P})+\mathrm{D} 1_{0} \cdot \text { Freq }_{\mathrm{f}}+\mathrm{E} 1_{0} \cdot \operatorname{Int}_{\mathrm{f}}+\mathrm{F} 1_{0} \\
\mathrm{~A}_{\mathrm{d}}=\mathrm{B} 2_{0} \cdot(\Delta \mathrm{P})^{2}+\mathrm{C} 2_{0} \cdot(\Delta \mathrm{P})+\mathrm{D} 2_{0} \cdot \text { Freq }_{\mathrm{d}}+\mathrm{E} 2_{0} \cdot \operatorname{Int}_{\mathrm{d}}+\mathrm{F} 2_{0} \\
\mathrm{~A}_{\mathrm{c}}=\mathrm{B} 3_{0} \cdot(\Delta \mathrm{T})^{2}+\mathrm{C} 3_{0} \cdot(\Delta \mathrm{T})+\mathrm{D} 3_{0} \cdot \text { Freq }_{\mathrm{c}}+\mathrm{E} 3_{0} \cdot \text { Int }_{\mathrm{c}}+\mathrm{F} 3_{0}
\end{gathered}
$$

where $\mathrm{A}^{*}$ is the proportion of direct economic losses of climate change to the total economic output, $A_{f}$ is the proportion of direct economic losses caused by annual precipitation and floods to the total economic output, $A_{d}$ is the proportion of direct economic losses caused by annual precipitation and drought to the total economic output, $\mathrm{A}_{\mathrm{c}}$ is the proportion of direct economic losses caused by annual average temperature and low temperature to the total economic output, $\Delta \mathrm{T}$ is the annual average temperature rise, $\Delta \mathrm{P}$ is the change in annual precipitation, Freq $_{\mathrm{f}}$ is the frequency of floods, Int $_{\mathrm{f}}$ is the intensity of the flood, Freq $q_{d}$ is the frequency of drought, Int $_{d}$ is the intensity of the drought, Freq ${ }_{c}$ is the low temperature frequency, $\mathrm{Int}_{\mathrm{c}}$ is the intensity of the low temperature. $\mathrm{B} 1_{0}, \mathrm{C} 1_{0}, \mathrm{D} 1_{0}, \mathrm{E} 1_{0}, \mathrm{~F} 1_{0}$, $\mathrm{B} 2_{0}, \mathrm{C} 2_{0}, \mathrm{D} 2_{0}, \mathrm{E} 2_{0}, \mathrm{~F} 2_{0}, \mathrm{~B} 3_{0}, \mathrm{C} 3_{0}, \mathrm{D} 3_{0}, \mathrm{E} 3_{0}$, and $\mathrm{F} 3_{0}$ are parameters to be estimated. Finally, a is the proportion of the three main economic losses caused by extreme climate change events to the total economic losses.

The number of months during the year when the monthly temperature exceeds (is below) the upper (lower) threshold of the extreme temperature events is called the frequency of extreme high-temperature (low-temperature) events, and the ratio of the sum of extreme temperature values to the corresponding frequency is called the intensity of the extreme high-temperature (low-temperature) event.

\section{Results}

\subsection{The Result of the Regression}

The results of multiple statistical regression fitting show that the goodness of fit is $R^{2}=0.04705$, the parameters to be estimated are $\mathrm{B}_{0}=0.00035, \mathrm{C}_{0}=4.29 \times 10^{-8}, \mathrm{D}_{0}=-5.72 \times 10^{-6}$, and $\mathrm{E}_{0}=0.0048$.

The results of multivariate statistical regression fitting are shown in Table 1. 
Table 1. Multivariate statistical regression results.

\begin{tabular}{|c|c|c|c|c|c|c|}
\hline Extreme Climate Change Events & $R^{2}$ & $\boldsymbol{B}_{0}$ & $C_{0}$ & $D_{0}$ & $E_{0}$ & $F_{0}$ \\
\hline Flood $A_{f}$ & 0.8752 & $-1.8672 \times 10^{-7}$ & $-1.5587 \times 10^{-5}$ & -0.004772 & 0.0001123 & 0.002773 \\
\hline Drought $A_{d}$ & 0.6764 & $4.0125 \times 10^{-8}$ & $-1.0611 \times 10^{-5}$ & 0.0006936 & $2.2215 \times 10^{-5}$ & 0.001596 \\
\hline Low temperature $A_{c}$ & 0.1911 & $-3.1416 \times 10^{-5}$ & 0.0004078 & 0.0001239 & $8.6189 \times 10^{-6}$ & 0.0004389 \\
\hline
\end{tabular}

In addition, SPSS software was used for an independent sample $t$ test, and independent samples from the population were used to infer whether there were significant differences in the mean of the population. The results of the independent sample $t$ test are shown in Tables 2-4.

Table 2. Independent sample $t$ test for regression function (3).

\begin{tabular}{|c|c|c|c|c|c|c|c|c|c|}
\hline & \multicolumn{2}{|c|}{$\begin{array}{c}\text { Levene Test for } \\
\text { Variance } \\
\text { Equation }\end{array}$} & \multicolumn{7}{|c|}{$T$-Test of Mean Equation } \\
\hline & \multirow[t]{2}{*}{$\mathbf{F}$} & \multirow[t]{2}{*}{ Sig. } & \multirow[t]{2}{*}{$\mathbf{t}$} & \multirow[t]{2}{*}{ df } & \multirow[t]{2}{*}{$\begin{array}{l}\text { Sig. (Two } \\
\text { Sides) }\end{array}$} & \multirow{2}{*}{$\begin{array}{c}\text { Mean } \\
\text { Difference }\end{array}$} & \multirow{2}{*}{$\begin{array}{l}\text { Standard } \\
\text { Error } \\
\text { Value }\end{array}$} & \multicolumn{2}{|c|}{$\begin{array}{c}\text { 95\% Confidence Interval of } \\
\text { Difference }\end{array}$} \\
\hline & & & & & & & & Lower Limit & Upper Limit \\
\hline $\begin{array}{l}\text { Hypothesis } \\
\text { variance is } \\
\text { equivalent }\end{array}$ & 1.092 & 0.307 & -0.576 & 22 & 0.571 & -242.90833 & 422.04949 & -1118.18540 & 632.36873 \\
\hline $\begin{array}{c}\text { Hypothesis } \\
\text { variance is } \\
\text { nonequivalent }\end{array}$ & & & -0.576 & 21.796 & 0.571 & -242.90833 & 422.04949 & -1118.66138 & 632.84471 \\
\hline
\end{tabular}

Table 3. Independent sample $t$ test for regression function (4).

\begin{tabular}{|c|c|c|c|c|c|c|c|c|c|}
\hline & \multicolumn{2}{|c|}{$\begin{array}{c}\text { Levene Test for } \\
\text { Variance } \\
\text { Equation }\end{array}$} & \multicolumn{7}{|c|}{$T$-Test of Mean Equation } \\
\hline & \multirow[t]{2}{*}{$\mathbf{F}$} & \multirow[t]{2}{*}{ Sig. } & \multirow[t]{2}{*}{$\mathbf{t}$} & \multirow[t]{2}{*}{ df } & \multirow{2}{*}{$\begin{array}{l}\text { Sig. (Two } \\
\text { Sides) }\end{array}$} & \multirow{2}{*}{$\begin{array}{c}\text { Mean } \\
\text { Difference }\end{array}$} & \multirow{2}{*}{$\begin{array}{l}\text { Standard } \\
\text { Error } \\
\text { Value }\end{array}$} & \multicolumn{2}{|c|}{$\begin{array}{c}\text { 95\% Confidence Interval of } \\
\text { Difference }\end{array}$} \\
\hline & & & & & & & & Lower Limit & Upper Limit \\
\hline $\begin{array}{l}\text { Hypothesis } \\
\text { variance is } \\
\text { equivalent }\end{array}$ & 1.667 & 0.210 & -0.785 & 22 & 0.441 & -338.54167 & 431.23541 & -1232.86918 & 555.78584 \\
\hline $\begin{array}{l}\text { Hypothesis } \\
\text { variance is } \\
\text { nonequivalent }\end{array}$ & & & -0.785 & 21.607 & 0.441 & -338.54167 & 431.23541 & -1233.81359 & 556.73025 \\
\hline
\end{tabular}

Table 4. Independent sample $t$ test for regression function (5).

\begin{tabular}{|c|c|c|c|c|c|c|c|c|c|}
\hline & \multicolumn{2}{|c|}{$\begin{array}{c}\text { Levene Test for } \\
\text { Variance } \\
\text { Equation }\end{array}$} & \multicolumn{7}{|c|}{$T$-Test of Mean Equation } \\
\hline & \multirow[t]{2}{*}{$\mathbf{F}$} & \multirow[t]{2}{*}{ Sig. } & \multirow[t]{2}{*}{$\mathbf{t}$} & \multirow[t]{2}{*}{ df } & \multirow{2}{*}{$\begin{array}{l}\text { Sig. (Two } \\
\text { Sides) }\end{array}$} & \multirow{2}{*}{$\begin{array}{c}\text { Mean } \\
\text { Difference }\end{array}$} & \multirow{2}{*}{$\begin{array}{l}\text { Standard } \\
\text { Error } \\
\text { Value }\end{array}$} & \multicolumn{2}{|c|}{$\begin{array}{l}\text { 95\% Confidence Interval of } \\
\text { Difference }\end{array}$} \\
\hline & & & & & & & & Lower Limit & Upper Limit \\
\hline $\begin{array}{l}\text { Hypothesis } \\
\text { variance is } \\
\text { equivalent }\end{array}$ & 0.125 & 0.727 & -0.264 & 22 & 0.795 & -109.95000 & 417.20564 & -975.18154 & 755.28154 \\
\hline $\begin{array}{l}\text { Hypothesis } \\
\text { variance is } \\
\text { nonequivalent }\end{array}$ & & & -0.264 & 21.875 & 0.795 & -109.95000 & 417.20564 & -975.46931 & 755.56931 \\
\hline
\end{tabular}

According to Tables 2-4, given the significance level of 0.05 , SPSS statistical decision-making is tested in two steps. The first step is the F test of whether the difference of the total variance is significant. The observed values of the F statistic in this test are 1.092, 1.667, and 0.125 , respectively, and the corresponding probabilistic $p$ values are $0.307,0.210$, and 0.727 respectively, which are all higher than the significant level of 0.05 . It is considered that there is no significant difference in the total variance. 
The second step is the test of the total mean difference. In the first step, since there is no significant difference in the total variance, we should look at the $t$ test results of the first line. The observed values of the $t$-statistics were $-0.576,-0.785$, and -0.264 , respectively. The corresponding double tail probability $p$ values were $0.571,0.441$, and 0.795 , which were all higher than the significant level of 0.05 . It was considered that there was no significant difference in the overall mean value. The $95 \%$ confidence interval of the total mean test spans 0 , which also confirms the inference that there is no significant difference in the total mean. Therefore, using the improved IAM economic damage function to estimate the economic loss of three types of disasters in China, there is no significant difference between the fitting value samples and the real value samples. The improved IAM economic damage function can reflect the economic loss caused by meteorological events and extreme climate events well.

Overall, based on the consideration of both the annual average temperature and the average annual precipitation, the continued introduction of the frequency and intensity of extreme flood, drought, and low temperature significantly improves the goodness of fit of the damage function. According to the classification, the goodness of fit of the flood damage function reaches 0.8572 , and the goodness of fit of the drought economic damage function is second, reaching 0.6764 . The low-degree economic damage function has the lowest goodness of fit, 0.0407 , and the uncertainty of the damage function may be brought about by the low temperature.

\subsection{Simulation Effect of IAM Damage Function}

Based on the current mainstream RICE model, one of the IAM models, the results of the simulated economic loss of China's regional climate change are historically verified, and the simulation capability of IAM in the economic impact assessment of climate change is evaluated. The historical data is the proportion of economic loss to the GDP, and the economic loss is obtained from the Statistical Yearbook of Meteorological Disasters (2005-2016). In the RICE model, the climate-to-economic feedback module is the damage function of the RICE model [10], in which the numerator indicates the damaging effects of greenhouse gas reduction measures on the economy, and the denominator indicates the extent to which temperature rise affects economic production. Figures 6 and 7 compare the simulation results of the climate change economic loss of the RICE model with the true value of climate-related economic damage in China. The climate change factor input into the RICE model in Figure 6 is the global average temperature rise of the climate module output in the model, while that in Figure 7 is the average regional temperature rise in China. The simulation results of the RICE model in Figure 1 deviate significantly from the historical climate economic damage value of China (green line), which is mainly due to the fact that the impact and intensity of climate change impacts on the economy in IAM are calibrated by the average data of existing studies on a global scale, resulting in a failure to reflect regional climate change impacts [18]. However, global climate change is not in sync with regional climate change trends. The global average temperature rise has increased year by year, while the average temperature in China has not increased year by year. 


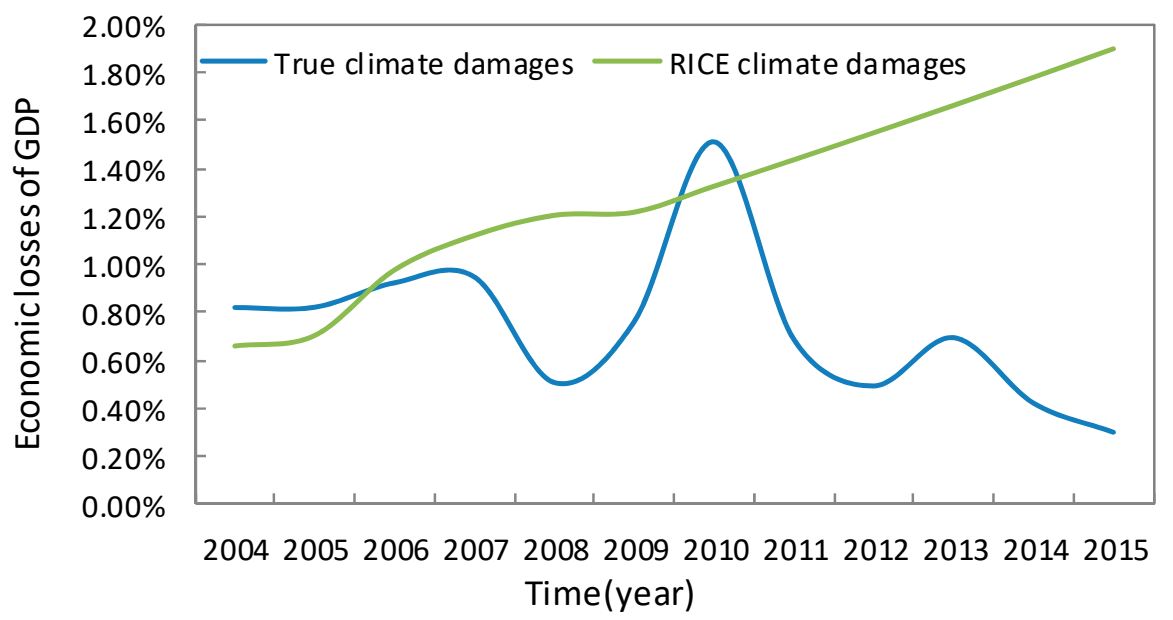

Figure 6. The simulation results of climate-related economic losses created by the RICE model (global temperature).

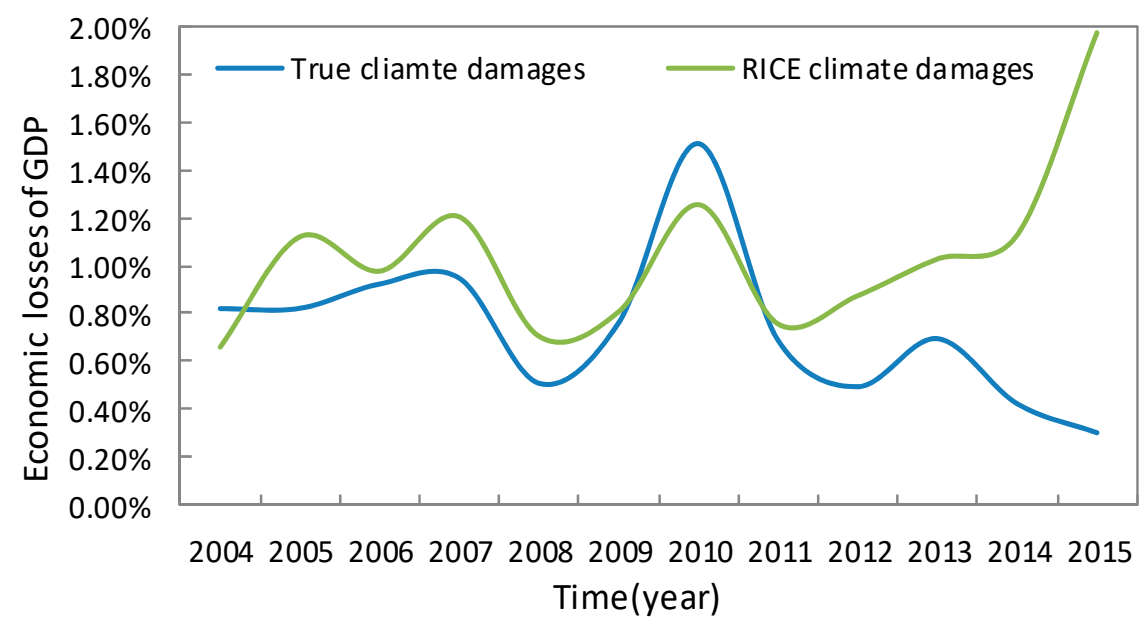

Figure 7. The simulation results of climate-related economic losses created by the RICES model (China's temperature).

Figure 8 is a simulation effect diagram of the improved multi-climate factor IAM damage function and the RICE model damage function for China's actual economic losses. The damage function in the RICE model that reflects the impact of the climate on the economy is in the form of the Nordhaus mode. Even if the climate element of the input damage function is the actual average temperature rise in China, the results can basically simulate the change trend of the impact of climate change in the previous period. Once it reaches the end of the simulation, especially during 2011-2015, the simulation effect of the RICE model clearly deviates from the actual economic losses of climate change in China (green line). Compared with the RICE model, the improved multi-climate factor IAM damage function is closer to China's actual economic losses related to climate change (red line). 


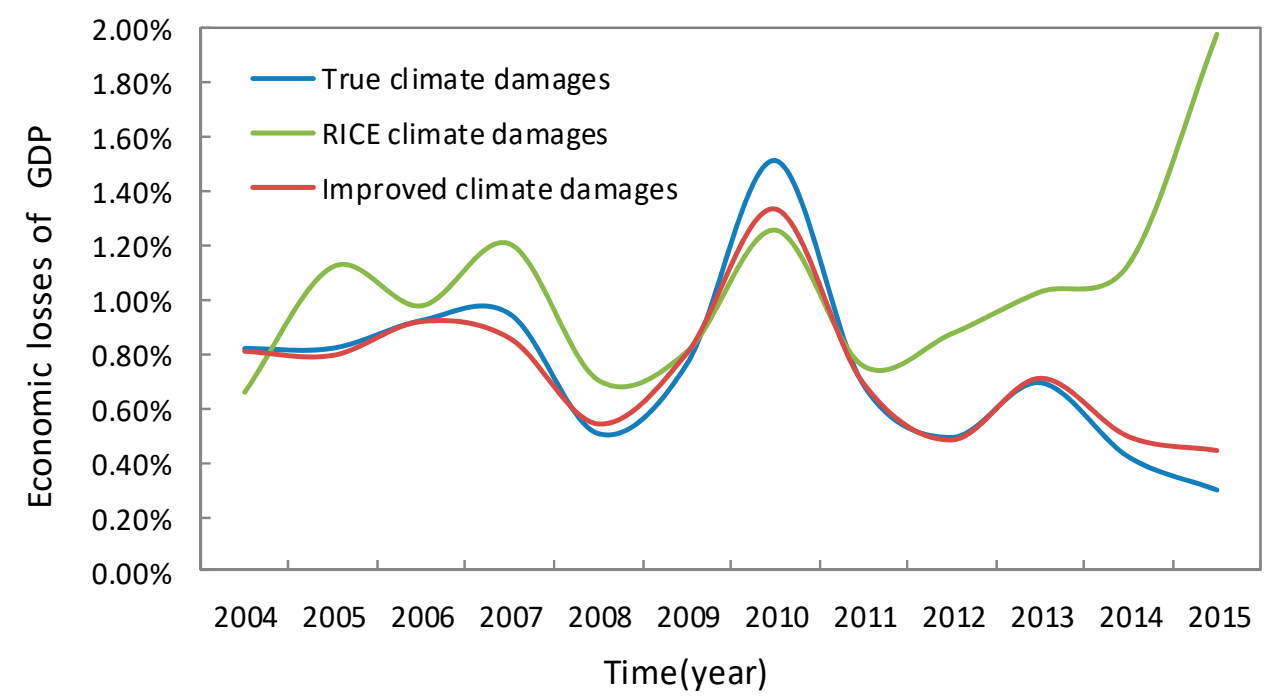

Figure 8. Comparison of the simulation results by the RICE model and the improved damage function.

Furthermore, the simulated effects of the improved multi-climate factor IAM damage function and RICE model damage function on China's actual economic loss ratio are statistically analyzed and tested, as shown in Table 5. Through a correlation analysis between the simulated value and the real value, it can be seen that the correlation coefficient of the RICE model is -0.0966 , and the correlation coefficient of the improved IAM multi-climate factor damage function is 0.9908 , indicating that the simulated value of the improved IAM multi-climate factor damage function has a stronger correlation with the real value. The z-test is performed on the simulated value and the real value: Double sampling mean value analysis. The results show that the $\mathrm{z}$ value of the damage function of the RICE model is 2.494, which is greater than the critical value of the one-tailed $z$ value of 1.6449 , and greater than the critical value of the two-tailed $\mathrm{z}$ value of 1.96 . The $p$ value of the one-tailed test $(\mathrm{Z} \leq \mathrm{z})$ is 0.0063 , less than the 0.05 significance level, and the $p$ value of the two-tailed test $(Z \leq z)$ is 0.0126 , less than the 0.05 significance level. According to the relationship between the $Z$ value and the significance of difference in Table 3, the RICE model damage function simulation value and the real value have a significant difference at the 0.05 significance level. The $\mathrm{z}$ value of the improved multi-climate factor IAM damage function is 0.008 , which is less than the critical value of the one-tailed $\mathrm{z}$ value of 1.6449 , and less than the critical value of the two-tailed $z$ value of 1.96. The $p$ value of the one-tailed test $(Z \leq z)$ is 0.4968 , greater than the 0.05 significance level. The $p$ value of the two-tailed test $(Z \leq z)$ is 0.9936 , greater than the 0.05 significance level. According to the relationship between the $Z$ value and the significance of the difference in Table 3 , the simulated value of the improved IAM multi-climate factor damage function has no significant difference from the true value at the 0.05 significance level. The analysis of variance for the simulated and real values: One-factor analysis of variance has also been made. The results show that the test statistic F of the RICE model damage function is 5.5504, which is greater than the F-threshold value of 4.3512. It can be considered that the F-value is significant at the 0.05 level, that is, there is a significant difference between the simulated value of the RICE model damage function and the true value at the 0.05 significance level. The test statistic $F$ of the improved multi-climate factor IAM damage function is $5 \times 10^{-5}$, which is less than the F-threshold value of 4.3512. It can be considered that the F-value is not significant at the 0.05 level, that is, there is no significant difference between the simulated IAM multi-climate factor damage function simulation value and the true value at the 0.05 significance level. 
Table 5. Statistical comparison of the simulation results by the RICE model and the improved damage function.

\begin{tabular}{|c|c|c|}
\hline $\begin{array}{c}\text { Verification of } \\
\text { Simulation Effect }\end{array}$ & Damage Function of RICE Model & The Improved Damage Function \\
\hline correlation analysis & $\begin{array}{c}\text { correlation coefficient }=-0.0966 \\
\text { Weak correlation }\end{array}$ & $\begin{array}{l}\text { correlation coefficient }=0.9908 \\
\text { Strong correlation }\end{array}$ \\
\hline $\begin{array}{l}Z \text { test: double sample } \\
\text { mean analysis }\end{array}$ & $\begin{array}{c}|z|=2.494>\mathrm{z} \text { one-side test value } \\
1.6449 P(\mathrm{Z} \leq \mathrm{z}) \mathrm{t} \text { value }=0.0063<0.05 \\
|z|=2.494>\mathrm{z} \text { one-side test value } 1.96 \\
P(\mathrm{Z} \leq \mathrm{z}) \mathrm{t} \text { value }=0.0126<0.05 \\
\text { Significant difference }\end{array}$ & $\begin{array}{c}|z|=0.008<\mathrm{z} \text { one-side test value } \\
1.6449 P(\mathrm{Z} \leq \mathrm{z}) \mathrm{t} \text { value }=0.4968>0.05 \\
|z|=0.008<\mathrm{z} \text { one-side test value } 1.96 \\
P(\mathrm{Z} \leq \mathrm{z}) \mathrm{t} \text { value }=0.9936>0.05 \\
\quad \text { not significant difference }\end{array}$ \\
\hline $\begin{array}{l}\text { ANOVA: One-way } \\
\text { ANOVA }\end{array}$ & $\begin{array}{c}\mathrm{F}=5.5504>\mathrm{F} \text { crit }=4.3512 \\
\text { Significant difference }\end{array}$ & $\begin{array}{c}\mathrm{F}=5 \times 10^{-5}<\mathrm{F} \text { crit }=4.3512 \\
\text { not significant difference }\end{array}$ \\
\hline
\end{tabular}

In summary, the improved traditional IAM damage function has a significant effect. The improved multi-climate factor IAM damage function is closer to the actual economic losses attributable to climate change in China, and the coupling degree of the damage function connecting climate factors and economic indicators on a regional scale is enhanced. The improved damage function, to a certain extent, compensates for the deficiency of the traditional IAM damage function that only uses temperature rise as a factor of climate change. Additionally, the damage function also considers extreme climate change events, which can improve the accuracy of the estimates of economic loss from climate change.

\section{Conclusions}

In the current IAM, the damage function cannot work well, thus causing a bottleneck that limits the development of IAMs. The IAM does not include information on the economic losses caused by different categories of disasters, resulting in an inability to directly describe the huge impact of extreme weather events on the economy. The other specific manifestation is that the early climate models only calculate the temperature changes, so IAMs can use temperature rise as the only factor of climate change, and the loss is directly associated with the temperature rise, because it lacks modules that reflect precipitation and other information. The mode and intensity of climate change impacts on the economy in IAM are calibrated through the average value at a global scale. Therefore, it cannot reflect regional climate change impacts. The climate element in IAM uses only the global average as the input, so it does not show regional differences and inner-annual changes. These problems were improved in this paper.

China was selected as the research area, and this paper improved the IAM damage function. Precipitation was introduced, the impact of regional climate change factors was refined, and the method of reflecting the economic impact of all climate change factors only via temperature rise was removed. The information on extreme temperature and extreme precipitation events was extracted based on the climate change characteristics of the monthly scale temperature and precipitation. Based on different disaster categories, an economic damage function, including average and extreme states of climate, was developed. The traditional IAM method of estimating the damage function of the annual average of climate change was changed, and a multi-climate factor IAM damage function applicable to the particular characteristics of China's regions was constructed.

First, by observing the scatter diagram of regional economic losses and various climate indicators in China, the mechanism for improving the IAM damage function was clarified. From a statistical point of view, the relationship between various economic loss indicators and average climate indicators, including flood, drought, and low temperature damage functions, is quadratic, and the relationship between the various economic loss indicators and the extreme climate indicators is linear.

Furthermore, a multi-climate factor IAM damage function was constructed, wherein new information on precipitation and extreme weather events was introduced, and the economic impacts 
of average climate indicators, such as annual average temperature and annual precipitation, as well as extreme climate indicators, such as the frequency and intensity of floods, droughts, and low temperature, were considered. Multivariate statistical regression results showed that the goodness of fit of the classified damage functions was significantly improved. Additionally, the goodness of fit of the flood, drought, and low-temperature economic damage functions were $0.8572,0.6764$, and 0.0407 , respectively.

Finally, the simulation effect of the multi-climate factor IAM damage function was assessed. The statistical results showed that the correlation coefficient between the simulated value of the improved multi-climate factor IAM damage function and the real value is as high as 0.9908 , which indicates a strong correlation. Single-factor variance analysis demonstrated that the simulated value of the improved multi-climate factor IAM damage function and the real values had no significant difference at the 0.05 significant level. Compared with the RICE model, the improved multi-climate factor IAM damage function was closer to the actual economic losses caused by meteorological events in China, and the coupling degree of the damage function connecting climate factors and economic indicators on a regional scale was enhanced. To a certain extent, the deficiency of the traditional IAM damage function using only temperature rise as a factor of climate change, and the inadequacy of demarcating the damage function with only the average state temperature and precipitation, thus ignoring the economic loss of the extreme state of the climate factor, were compensated for.

The result shows that we have improved the damage function to some extent. However, much work remains to be done to clearly show how climate change affects economics.

Author Contributions: Conceptualization, C.L.; H.Z. and Z.W.; methodology, C.L.; H.Z.; software, H.Z.; validation, C.L., and Z.W.; formal analysis, C.L.; H.Z. and Z.W.; data curation, H.Z.; writing-original draft preparation, C.Li.; H.Z.; writing—review and editing, C.L.; supervision, Z.W.

Funding: This research was funded by the National Key R\&D Program Subsidized Projects (2016YFA0602700) and the China Postdoctoral Science Foundation (2018M641297).

Conflicts of Interest: The authors declare no conflict of interest.

\section{References}

1. Revesz, R.L.; Howard, P.H.; Arrow, K.; Goulder, L.H.; Kopp, R.E.; Livermore, M.A.; Oppenheimer, M.; Sterner, T. Global warming: Improve economic models of climate change. Nature 2014, 508, $173-175$. [CrossRef] [PubMed]

2. Nordhaus, W.D. To slow or not to slow: The economics of the greenhouse effect. Econ. J. 1991, 101, 920-937. [CrossRef]

3. Collins, W.D.; Craig, A.P.; Truesdale, J.E.; Vincent Di Vittorio, A.; Jones, A.; Bond-Lamberty, B.; Calvin, K.V.; Edmonds, J.A.; Kim, S.H.; Thomson, A.M.; et al. The integrated Earth System Model (iESM): Formulation and functionality. Geosci. Model Dev. 2015, 8, 2203-2219. [CrossRef]

4. $\quad$ Dong, W.; Yuan, W.; Teng, F.; Hao, Z.; Zheng, J.; Wei, Z.; Chou, J.; Liu, C.; Qi, T.; Yang, S.; et al. Coupling arth System Model and Integrated Assessment Model. Adv. Earth Sci. 2016, 31, 1215-1219.

5. Hope, C. The Marginal Impact of CO2 from PAGE2002: An Integrated Assessment Model Incorporating the IPCC's Five Reasons for Concern. Integr. Assess. 2006, 6, 19-56.

6. Tol, R.S.J. Multi-Gas Emission Reduction for Climate Change Policy: An Application of Fund. Energy J. 2006, 27, 235-250. [CrossRef]

7. Botzen, W.J.W.; van den Bergh, J.C.J.M. How sensitive is Nordhaus to Weitzman? Climate policy in DICE with an alternative damage function. Econ. Lett. 2012, 117, 372-374.

8. Anthoff, D.; Tol, R.S.J. Climate damages in the FUND model: A comment. Ecol. Econ. 2012, 81, 42. [CrossRef]

9. Tol, R.S.J. On the Uncertainty About the Total Economic Impact of Climate Change. Environ. Resour. Econ. 2012, 53, 97-116. [CrossRef]

10. Nordhaus, W.D. The 'DICE' Model: Background and Structure of a Dynamic Integrated Climate-Economy Model of the Economics of Global Warming; Cowles Foundation for Research in Economics, Yale University: New Haven, CT, USA, 1992. 
11. Nordhaus, W.D.; Yang, Z. A Regional Dynamic General-Equilibrium Model of Alternative Climate-Change Strategies. Am. Econ. Rev. 1996, 86, 741-765.

12. Tol, R.S.J. The damage costs of climate change toward more comprehensive calculations. Environ. Resour. Econ. 1995, 5, 353-374.

13. Tol, R.S.J. On the optimal control of carbon dioxide emissions: An application of FUND. Environ. Model. Assess. 1997, 2, 151-163. [CrossRef]

14. Ackerman, F.; Munitz, C. A critique of climate damage modeling: Carbon fertilization, adaptation, and the limits of FUND. Energy Res. Soc. Sci. 2016, 12, 62-67. [CrossRef]

15. Ackerman, F.; Munitz, C. Climate damages in the FUND model: A disaggregated annualysis. Ecol. Econ. 2012, 77, 219-224. [CrossRef]

16. Anthoff, D.; Rose, S.K.; Tol, R.S.J.; Waldhoff, S. Regional and Sectoral Estimates of the Social Cost of Carbon: An Application of FUND; Social Science Electronic Publishing: New York, NY, USA, 2011.

17. Peck, S.C.; Teisberg, T.J. CETA: A Model for Carbon Emissions Trajectory Assessment. Energy J. 1992, 13, 55-78. [CrossRef]

18. Hope, C.; Anderson, J.; Wenman, P. Policy annualysis of the greenhouse effect: An application of the PAGE model. Energy Policy 1993, 21, 327-338. [CrossRef]

19. Burke, M.; Davis, W.M.; Diffenbaugh, N.S. Large potential reduction in economic damages under UN mitigation targets. Nature 2018, 557, 549-553. [CrossRef] [PubMed]

20. Van Dingenen, R.; Dentener, F.J.; Raes, F.; Krol, M.C.; Emberson, L.; Cofala, J. The global impact of ozone on agricultural crop yields under current and future air quality legislation. Atmos. Environ. 2009, 43, 604-618. [CrossRef]

21. Zheng, J.; Hao, Z.; Fang, X.; Ge, Q. Changing characteristics of extreme climate events during past 2000 years in China. Adv. Earth Sci. 2014, 33, 3-12.

22. Chou, J.; Dong, W.; Yan, X. The Impact of Climate Change on the Socioeconomic System: A Mechanistic Annualysis. Chin. J. Atmos. Sci. 2016, 1, 191-200.

23. Pan, X.; Zhai, P. Annualysis of Surface Air Temperature Extremum. Meteorological 2002, 28, $28-31$.

24. Trenberth, K.E.; Jones, P.D.; Ambenje, P.; Bojariu, R.; Easterling, D.; Klein, A.; Parker, D.; Rahimzadeh, F.; Renwick, J.; Rusticucci, M.; et al. Observations: Surface and atmospheric climate change. In Climate Change 2007: The Physical Science Basis. Contribution of Working Group I to the Forth Assessment Report of the Intergovernmental Panel on Climate Change; Cambridge University Press: Cambridge, UK; New York, NY, USA, 2007.

25. Karl, T.R.; Knight, R.W.; Easterling, D.R.; Quayle, R.G. Indices of Climate Change for the United States. Bull. Am. Meteorol. Soc. 1996, 77, 279-292. [CrossRef]

26. Jones, P.D.; Horton, E.B.; Folland, C.K.; Hulme, M.; Parker, D.E.; Basnett, T.A. The Use of Indices to Identify Changes in Climatic Extremes. Clim. Change 1999, 42, 131-149. [CrossRef]

27. Zhai, P.; Pan, X. Change in Extreme Temperature and Precipitation over Northern China During the Second Half of the 20th Century. Acta Geogr. Sin. 2003, 58, 1-10.

28. Ren, F.; Zhai, P. Study on Changes of China's Extreme Temperatures During 1951-1990. Chin. J. Atmos. Sci. 1998, 22, 217-227.

29. Yang, J.; Sun, J.; Reiner, S. Trends in Frequency and Intensity of Extreme Precipitation at Four German Stations. Period. Ocean Univ. China 2010, 1, 23-30.

30. Wang, F.; Ding, Y.; Fan, J. The diagnosis research for extremum statistical character of summer's daily precipitation in Jiangsu province. Sci. Atmos. Sin. 2002, 22, 435-443.

31. Zhou, X.; Zhang, J.; Zheng, H.; Pan, H. Effect of Climate Warming for the Extreme Weather Climate Event in Heilongjiang Province. Meteorological 2004, 30, 47-50.

32. Jones, P.D.; Briffa, K.R.; Barnett, T.P.; Tett, S.F.B. High-resolution pale climatic record for the last millennium: Interpretation, integration and comparison with GCM control-run temperature. Holocene 1998, 8, 779-787. [CrossRef]

33. Cheng, B.; Ding, Y.; Wang, F. A Diagnosis Method of the Extreme Features of Weather and Climate in Time Series Based on Non-Normal Distribution. Chin. J. Atmos. Sci. 2003, 27, 920-928.

34. Su, B.; Jiang, T.; Ren, G.; Chen, Z. Observed trends of Precipitation Extremes in the Yangtze River Basin during 1960 to 2004. Adv. Clim. Change Res. 2007, 3, 9-14. 
35. Dong, W.; Chou, J.; Feng, G. A New Economic Assessment Index for the Impact of Climate Change on Grain Yield. Adv. Atmos. Sci. 2007, 24, 336-342. [CrossRef]

36. Alexander, L.V.; Zhang, X.; Peterson, T.C.; Caesar, J.; Gleason, B.A.; Tank, A.; Haylock, M.; Collins, D.; Trewin, B.; Rahimzadeh, F.; et al. Global observed changes in daily climate extremes of temperature and precipitation. J. Geophys. Res. Atmos. 2006, 111, 1042-1063. [CrossRef]

37. Bonsal, B.R.; Zhang, X.; Vincent, L.A.; Hogg, W.D. Characteristics of Daily and Extreme Temperatures over Canada. J. Clim. 2001, 14, 1959-1976. [CrossRef]

38. Frich, P.; Alexander, L.V.; Dellamarta, P.; Gleason, B.; Haylock, M.; Amg Klein, T.; Peterson, T.C. Observed coherent changes in climatic extremes during the second half of the twentieth century. Clim. Res. 2002. [CrossRef]

39. Shi, P. Theory and practice on disaster system research in a fifth time. J. Nat. Disasters 2009, 18, 1-9.

40. Meyer, V.; Becker, N.; Markantonis, V.; Schwarze, R.; van den Bergh, J.C.J.M.; Bouwer, L.M.; Bubeck, P.; Ciavola, P.; Genovese, E.; Green, C.; et al. Assessing the costs of natural hazards-state of the art and knowledge gaps. Nat. Hazards Earth Syst. Sci. 2013, 13, 1351-1373. [CrossRef]

41. Fankhauser, S. Protection versus retreat: The economic costs of sea-level rise. Environ. Plan. A 1995, 27, 299-319. [CrossRef]

42. Tol, R.S.J. Estimates of the damage costs of climate change. Part 1: Benchmark estimates. Environ. Resour. Econ. 2002, 21, 47-73. [CrossRef]

43. Rehdanz, K.; Maddison, D. Climate and happiness. Ecol. Econ. 2005, 52, 111-125. [CrossRef]

44. Mendelsohn, R.; Morrison, W.; Schlesinger, M.E.; Andronova, N.G. Country-specific market impacts of climate change. Clim. Change 2000, 45, 553-569. [CrossRef]

45. Maddison, D. The amenity value of the climate: The household production function approach. Resour. Energy Econ. 2003, 25, 155-175. [CrossRef]

46. Nordhaus, W.D. Geography and macroeconomics: New data and new findings. Proc. Natl. Acad. Sci. USA 2006, 103, 3510-3517. [CrossRef] [PubMed] 